\title{
EVALUATION OF THE IMMUNOMODULATORY ACTIVITY OF THE ALCOHOLIC EXTRACTS OF RUTA GRAVEOLENS LEAVES
}

\author{
PINKEE PANDEY*, ARCHANA MEHTA, SUBHADIP HAJRA \\ Lab of Plant Biotechnology, Dept. of Botany, School of Biological and Chemical Sciences, Dr. H. S. Gour Central University, Sagar 470003, \\ Madhya Pradesh, India \\ Email: pinkee.9d@gmail.com \\ Received: 20 Dec 2012 Revised and Accepted: 12 Jul 2016
}

\begin{abstract}
Objective: The present study was undertaken to evaluate the immunomodulatory activity of the alcoholic extracts of Ruta graveolens leaves in vivo.

Methods: Immunomodulatory activity was determined by neutrophil adhesion test, phagocytic activity, haemagglutinating antibody (HA) titre and delayed-type hypersensitivity (DTH) response.

Results: Oral administration of the extracts $(50,100,150$ and $200 \mathrm{mg} / \mathrm{kg}$ bw, p. o) evoked a significant (**P<0.01) increased in percent of neutrophil adhesion to nylon fibers. Both the extracts were also increased the antibody titre in a dose-dependent manner. Oral administration of both the compound significantly $\left({ }^{* *} \mathrm{P}<0.01\right)$ potentiated delayed type hypersensitivity reaction induced by sheep red blood cells and response towards phagocytosis in carbon clearance assay. In this study indicated that leaves extracts possesses potent immune-modulatory activity in a
\end{abstract} concentration-dependent manner. The response was statistically significant when compared with the control $\left(* \mathrm{P}<0.05,{ }^{* *} \mathrm{P}<0.01\right)$.

Conclusion: The study stated that Ruta graveolens leaves extracts showed a significant stimulation of the cell-mediated immunity as well as humoral immunity. Further investigations are required to determine its active constituents and also its mechanism of action.

Keywords: Immunomodulatory, Ruta graveolens, Alcoholic, Sheep red blood and phagocytosis

(C) 2016 The Authors. Published by Innovare Academic Sciences Pvt Ltd. This is an open access article under the CC BY license (http://creativecommons.org/licenses/by/4. 0/] DOI: http://dx.doi.org/10.22159/ijpps.2016v8i11.15531

\section{INTRODUCTION}

Immunomodulation is the regulation and modulation of immunity either by immunostimulation or by immune suppression [1]. There are two main categories of immunostimulators. The specific immunostimulatory are those which provide antigen specificity in immune response, such as vaccines or any antigen while the nonspecific immunostimulators are those which act irrespective of antigenic specificity to augment immune response of other antigens or stimulate components of the immune system without antigenic specificities, such as adjuvant and non-specific immune modulators [2]. Various natural adjuvant and synthetic agents such as levamisole, thidomide are used as immunostimulating agents, but the nowadays use of this agents are restricted due to its various side effects such as nephrotoxicity, hepatotoxicity, bone marrow suppression, gastrointestinal disturbances, hypertension, hirsutism and myalgia. Thus needs to alternative sources of medicine which may be natural sources. Plants have played a significant role in maintaining human health and improving the quality of human life and provided components of medicines, seasonings, beverages, cosmetics and dyes. Herbal medicine is based on the presence of plants secondary metabolites which promote health and alleviate illness. There are several herbs used in the indigenous system of medicines that can modulate the body's immune system. Phytochemicals such as polysaccharides, lectins, peptides, flavonoids, natural sulfur compounds and tannins have been known to modulate the immune system in various in vivo models [1, 3].

Ruta graveolens commonly known as rue belongs to the plant family Rutaceae. It is a woody, strongly aromatic, perennial herb, native to the southern Europe and northern Africa. Leaves are dissected innately into oblong or spoon-shaped segments, fleshy and usually covered with a powdery bloom. Whole plants are largely used in traditional system of medicine. Alcoholic and aqueous extracts of aerial parts reveled anti-inflammatory activity [4] while ethyl acetate extract of leaves has an antifungal activity [5]. Ethanolic, methanolic, chloroform and water stem extracts showed potent antimicrobial activity [6] while its alcoholic leaves extracts showed potent anthelmintic, in vitro antioxidant and $\alpha$-amylase inhibitory activity $[7,8]$. Methanolic extract of fresh leaves and tender stem showed antitumor activity [9].

However, there is no scientific report available in the literature on the immunomodulatory activity of Ruta graveolens leaves. Therefore, the present study was undertaken to evaluate the immunomodulatory activity of the alcoholic extracts of the Ruta graveolens leaves.

\section{MATERIALS AND METHODS}

\section{Plant material}

Ruta graveolens leaves were collected in the month of August 2009 from Sagar District, Madhya Pradesh, India. Further taxonomic identification was conducted by Professor Pradeep Mehta at the Department of Botany, Dr. H. S. Gour Central University, Sagar, MP, India. A voucher specimen no. (Bot/Her/1514) has been deposited at the Departmental herbarium, Department of Botany, Dr. H. S. Gour Central University, Sagar, (M. P) India.

\section{Preparation of the extracts}

After collection of plant material, leaves were washed in running tap water and dried in the shade for 6-7 $\mathrm{d}$ to prevent the loss of active phytoconstituents. Then the leaves were powdered using a mechanical grinder. The powdered plant materials (35g) were soaked in $500 \mathrm{ml}$ of $75 \%$ ethanol and methanol separately and stand for $72 \mathrm{~h}$. The crude extract was collected by filtration and evaporated under reduced pressure to give a blackish green amorphous mass (yield was $2.120 \mathrm{w} / \mathrm{w} ; 2.359 \mathrm{w} / \mathrm{w}$ ) for ethanolic and methanolic extracts respectively. Extractives were dissolved in distilled water to get desired concentrations.

\section{Drugs}

Accurately weighed quantities of the ethanol and methanol extracts were suspended in distilled water for preparation of desired dosages in the experiment. Cyclophosphamide was used as a 
standard immunosuppressant. Carbon ink suspension: Pelican AG ink, Germany, was diluted eight times with saline and used for the carbon clearance test in a dose of $10 \mathrm{ml} / \mathrm{kg}$ body weight of rats.

\section{Antigen}

Fresh blood was collected from sheep sacrificed in the local slaughter house. Sheep red blood cells (SRBCs) were washed three times in large volumes of Alsever's solution and adjusted to a concentration of $0.5 \times 10^{9}$ cells $/ \mathrm{ml}$ for immunization and challenge.

\section{Preliminary phytochemical screening}

Evaluation of phytochemicals was done by using standard procedure [10].

\section{Experimental animals}

Animal use protocol was approved by the Dr. Hari Singh Gour Central University, Sagar, MP, India (Reg. No.-379/01/ab/CPCSEA) and was in accordance with International Standard on the care and use of experimental animals (CCAC, 1993). Wister albino rats of either sex weighing between 125-150 gm were used for the experiment. Animals were housed under standard conditions of temperature $\left(25^{\circ} \mathrm{C}\right), 12 \mathrm{~h} / 12$ $\mathrm{h}$ light/dark cycles and fed with standard diet pellet (Hindustan lever Ltd. Kolkata, India) and water ad libitum.

\section{Toxicity assay}

Dried ethanolic and methanolic leaves extracts were dissolved in water and administered orally to different groups of rats in dosages ranging from 100 to $1000 \mathrm{mg} / \mathrm{kg}$ bw for the $L_{50}$ study using the modified method [11].

\section{Neutrophil adhesion test}

The neutrophil adhesion test was performed by Wilkonson [12]. The rats were divided into nine groups of six animals in each group. Group I, were served as control and received distilled water, whereas groups II to IX were pre-treated with different concentration of ethanolic and methanolic extracts of Ruta graveolens leaves (50, 100, 150 and $200 \mathrm{mg} / \mathrm{kg} \mathrm{bw}, \mathrm{p}$. o) for $14 \mathrm{~d}$. On day 14 of extracts treatment, blood samples were collected by puncturing retro-orbital plexus into heparinized vials and analyzed for total leukocyte (TLC) and differential leukocyte (DLC) count by fixing blood smears and staining with Field stain I and Leishman's stain. After the initial counts, blood samples were incubated with nylon fibre $\left(80 \mathrm{mg} / \mathrm{ml}\right.$ of blood sample) for $15 \mathrm{~min}$ at $37^{\circ} \mathrm{C}$. The incubated blood samples were again analyzed for TLC and DLC. The product of TLC and \% neutrophil gives neutrophil index (NI) of the blood sample. Percent of neutrophil adhesion was calculated as follows

$$
\text { Neutrophil adhition }(\%)=\frac{\text { NIu }- \text { NIt }}{\text { NIu }} \times 100
$$

Where NIu is the neutrophil index of untreated blood samples and NIt is the neutrophil index of treated blood samples.

\section{Carbon clearance assay}

Carbon clearance assay was done according to the method of Cheng et al., [13]. Animals were divided into ten groups of six rats in each group. Group, I animals served as control and received distilled water, Group II animals were treated with Cyclophosphamide (50 $\mathrm{mg} / \mathrm{kg}$ b.w. i. p for $3 \mathrm{~d}$ starting from day 4), Groups III-X animals were treated with ethanolic and methanolic extracts at the concentration of 50,100, 200 and $300 \mathrm{mg} / \mathrm{kg} \mathrm{bw}$, p. o. All the animals were treated as above from day 0 to day 7 . On $7^{\text {th }}$ day of treatment animals of the entire groups received an intravenous injection $(10 \mathrm{ml} / \mathrm{kg} \mathrm{bw})$ of Indian ink dispersion (pre-warmed at 37 ${ }^{\circ} \mathrm{C}$ ). Blood samples were collected from retro-orbital bleeding by using glass capillaries at an interval of $2 \mathrm{~min}$ and $10 \mathrm{~min}$ after the injection of ink dispersion. Blood samples were added to $4 \mathrm{ml}$ of $0.1 \%$ sodium carbonate solution to lyses the erythrocytes. The absorbance of these samples was measured at $675 \mathrm{~nm}$ using a spectrophotometer, after $10 \mathrm{~min}$ of blood collection of each animal. Rate of carbon clearance $(K)$ and phagocytic index $(\alpha)$ were calculated by using following formula:

$$
\begin{aligned}
& \text { Rate of carbon clearence }(K)=\frac{\log \text { OD2 }- \text { Log OD10 }}{\mathrm{T} 2-\mathrm{T} 1} \\
& \text { Phagocytic index }(\alpha)=\frac{\frac{\mathrm{K} 1}{3} \times \text { Body weight of animal }}{\text { Liver wt }+ \text { spleen wt }}
\end{aligned}
$$

Where OD2 is the log absorbance of blood at $2 \mathrm{~min}$; OD10 is log absorbance of blood at $10 \mathrm{~min}$; T2 is the last time point of blood collection; T1 is the first time point of blood collection.

The rate of carbon clearance and phagocytic index of treated group animals were compared with the control group animals.

\section{Haemagglutinating antibody (HA) titre}

Haemagglutinating antibody titre was done according to the method of Puri et al., [14]. The animals were immunized by injecting $0.1 \mathrm{ml}$ of SRBCs suspension containing $0.5 \times 10^{9}$ cells intraperitoneally on day zero. Blood samples were collected in microcentrifuge tubes from the individual animal by a retro-orbital puncture on $7^{\text {th }}$ day. The blood samples were centrifuged at $2500 \mathrm{rpm}$ for $10 \mathrm{~min}$ and serum was obtained (Kumar and Mishra, 2007). Antibody levels were determined by the hemagglutination technique. Equal volumes of individual serum samples of each group were pooled. Two-fold serial dilutions of pooled serum samples made in $25 \mu \mathrm{l}$ volume of normal saline in microtiter plates was added to $25 \mu \mathrm{l}$ of $1 \%$ suspension of SRBCs in saline. After mixing, the plates were incubated at $37{ }^{\circ} \mathrm{C}$ for $1 \mathrm{~h}$ and examined for haemagglutination under a microscope. The reciprocal of the highest dilution of the test serum agglutination was taken as the antibody titre.

\section{SRBC-induced delayed-type hypersensitivity (DTH) response}

SRBC-Induced Delayed-type hypersensitivity (DTH) response was carried out by Puri et al., (1993). The $R$. graveolens leaves extracts were administered orally on day 0 and continued till day 7 of a challenge. On $7^{\text {th }}$ day the thickness of right hind foot pad was measured using vernier caliper. The animals were then challenged by injecting $0.5 \times 10^{9}$ SRBCs in right hind foot pad. A footpad thickness was measured again 24, 48, 72 and $96 \mathrm{~h}$ after the challenge. The difference between pre and post challenge foot pad thickness expressed in mm was taken as a measure of (DTH), and the mean value obtained for treatment groups were compared with that of the control group. The data obtained was subjected to statistical analysis.

\section{Statistical analysis}

Data were expressed as the mean standard deviation $( \pm \mathrm{SD})$ of the means, and statistical analysis was carried out employing one-way ANOVA. Differences between the data were considered significant at ${ }^{*} \mathrm{p}<0.05$ and ${ }^{* *} \mathrm{p}<0.01$.

\section{RESULTS}

\section{Phytochemical screening}

The preliminary phytochemical screening of ethanolic extract of Ruta graveolens leaves revealed the presence of alkaloids, steroids, a phenolic compound, tannins and flavonoids while methanolic extract revealed the presence of alkaloids, flavonoids, steroids and glycosides as essential phytoconstituents.

\section{Toxicity study}

Acute toxicity studies with extracts revealed that $\mathrm{LD}_{50}$ is above 1000 $\mathrm{mg} / \mathrm{kg}$ body weight. There was no lethality in any of the groups after $7 \mathrm{~d}$ of treatment.

\section{Neutrophil adhesion test}

Effect of ethanolic and methanolic extracts on neutrophil activation by the neutrophil adhesion test is shown in (table 1 and 2). Ethanolic extract of Ruta graveolens leaves showed percentage of neutrophil adhesion as $24.20 \pm 1^{* *} .2,27.46 \pm 0.54^{* *}, 30.81 \pm 0.78^{* *}$ and $34.12 \pm 0.34^{* *}$ while methanolic extract showed percentage of neutrophil adhesion as $25.05 \pm 0.57^{* *}, \quad 26.54 \pm 1.3^{* *}, \quad 29.42 \pm 1.7^{* *}$ and $33.68 \pm 1.1^{* *}$ at the concentration of $50,100,150$ and $200 \mathrm{mg} / \mathrm{kg}$ bw respectively, whereas, in case of control group it was $18.95 \pm 0.59$. The results showed that ethanolic extract showed most potent neutrophils adhesion than methanolic extract at the concentration of $200 \mathrm{mg} / \mathrm{kg}$ bw. 
Table 1: Effect of ethanolic extract (mg/kg bw) of R. graveolens leaves on neutrophil adhesion test

\begin{tabular}{|c|c|c|c|c|c|c|c|c|}
\hline \multirow[t]{2}{*}{ Group } & \multirow{2}{*}{$\begin{array}{l}\text { Dose } \\
(\mathrm{mg} / \mathrm{kg})\end{array}$} & \multicolumn{2}{|c|}{ TLC $\left(10^{3} \mathrm{~mm}^{-3}\right)[\mathrm{X}]$} & \multicolumn{2}{|c|}{ Neutrophil [Y] } & \multicolumn{2}{|c|}{ Neutrophil index [XY] } & \multirow[t]{2}{*}{$\%$ of neutrophil adhesion } \\
\hline & & UB & FTB & UB & FTB & UB & FTB & \\
\hline Normal saline & - & $8.9 \pm 0.09$ & $8.25 \pm 0.17$ & $30.24 \pm 2.1$ & $26.44 \pm 1.24$ & $269.13 \pm 10.11$ & $218.13 \pm 12.2$ & $18.95 \pm 0.59$ \\
\hline \multirow{4}{*}{ RGLE } & 50 & $10.1 \pm 0.23$ & $8.9 \pm 0.23$ & $35.56 \pm 3.17$ & $30.59 \pm 2.2$ & $359.15 \pm 24.25$ & $272.25 \pm 32.1$ & $24.20 \pm 1.2^{* *}$ \\
\hline & 100 & $10.7 \pm 0.35$ & $9.1 \pm 0.33$ & $42.5 \pm 3.25$ & $36.25 \pm 2.15$ & $454.75 \pm 21.3$ & $329.88 \pm 38.2$ & $27.46 \pm 0.54^{* *}$ \\
\hline & 150 & $11.87 \pm 0.56$ & $9.63 \pm 0.25$ & $46.67 \pm 2.58$ & $39.8 \pm 3.7$ & $553.97 \pm 33.54$ & $383.27 \pm 44.7$ & $30.81 \pm 0.78^{* *}$ \\
\hline & 200 & $13.7 \pm 0.9$ & $10.7 \pm 0.46$ & $51.25 \pm 4.5$ & $43.23 \pm 4.0$ & $702.12 \pm 20.11$ & $462.56 \pm 22.1$ & $34.12 \pm 0.34^{* *}$ \\
\hline
\end{tabular}

UB: untreated blood; FTB: fiber treated blood; TLC= Total leukocyte count; RGLE: Ruta graveolens leaves ethanol extract. Values are mean \pm SD, $(\mathrm{n}=6)$. One way ANOVA followed by Dunnett's test, ${ }^{* *} \mathrm{p}<0.01$ significant.

Table 2: Effect of methanolic extract of $R$. graveolens leaves on neutrophil adhesion test

\begin{tabular}{|c|c|c|c|c|c|c|c|c|}
\hline \multirow[t]{2}{*}{ Group } & \multirow{2}{*}{$\begin{array}{l}\text { Dose } \\
\text { (mg/kg bw) }\end{array}$} & \multicolumn{2}{|c|}{ TLC $\left(10^{3} \mathrm{~mm}^{-3}\right)[\mathrm{X}]$} & \multicolumn{2}{|c|}{ Neutrophil [Y] } & \multicolumn{2}{|c|}{ Neutrophil index [XY] } & \multirow{2}{*}{$\begin{array}{l}\text { \% neutrophil } \\
\text { adhesion }\end{array}$} \\
\hline & & UB & FTB & UB & FTB & UB & FTB & \\
\hline $\begin{array}{l}\text { Normal } \\
\text { saline }\end{array}$ & - & $8.9 \pm 0.09$ & $8.25 \pm 0.17$ & $30.24 \pm 2.1$ & $26.44 \pm 1.24$ & $269.13 \pm 10.11$ & $218.13 \pm 12.2$ & $18.95 \pm 0.59$ \\
\hline \multirow[t]{4}{*}{ RGLM } & 50 & $9.75 \pm 0.11$ & $8.65 \pm 0.17$ & $33.56 \pm 1.5$ & $28.35 \pm 2.1$ & $327.21 \pm 13.2$ & $245.23 \pm 09.6$ & $25.05 \pm 0.57^{* *}$ \\
\hline & 100 & $10.55 \pm 0.27$ & $9.275 \pm 0.45$ & $43.44 \pm 2.2$ & $36.3 \pm 1.7$ & $458.29 \pm 22.1$ & $336.68 \pm 14.5$ & $26.54 \pm 1.3^{* *}$ \\
\hline & 150 & $11.275 \pm 0.7$ & $9.825 \pm 0.64$ & $46.67 \pm 2.4$ & $37.8 \pm 3.3$ & $526.2 \pm 33.4$ & $371.39 \pm 27.1$ & $29.42 \pm 1.7^{* *}$ \\
\hline & 200 & $12.98 \pm 0.4$ & $11.65 \pm 0.23$ & $53.3 \pm 2.33$ & $41.7 \pm 1.8$ & $691.83 \pm 12.1$ & $485.81 \pm 22.7$ & $33.68 \pm 1.1^{* *}$ \\
\hline
\end{tabular}

UB: untreated blood; FTB: fiber treated blood; TLC= Total leukocyte count; RGLM: Ruta graveolens leaves methanol extract. Values are mean \pm SD, $(n=6)$. One way ANOVA followed by Dunnett's test, ${ }^{* *} \mathrm{p}<0.01$ significant.

\section{Carbon clearance assay}

In carbon clearance test, extract treated with all groups showed concentration-dependent phagocytic activity when compared to control group. Ethanolic extract at the concentration 50, 100, 150 and 200 $\mathrm{mg} / \mathrm{kg}$ bw significantly increased phagocytic index $2.84 \pm 0.45^{*}$, $3.45 \pm 0.32^{* *}, 4.20 \pm 0.39^{* *}$ and $5.30 \pm 0.27^{* *}$ while in case of methanolic extract the level of the phagocytic index was $3.02 \pm 0.22 *, 3.6 \pm 0.45^{* *}$, $5.1 \pm 0.31^{* *}$ and $5.65 \pm 0.16^{* *}$ (table 3 ). Alcoholic extracts of $R$. graveolens leaves possessed macrophage stimulatory activity as evidenced by increased phagocytic index in carbon clearance test thus indicated stimulation of the reticuloendothelial system. The phagocytic activity of the reticuloendothelial system is generally measured by the rate of removal of carbon particles from the blood stream.

Table 3: Effect of ethanolic and methanolic extracts of $R$. graveolens leaves on phagocytic index

\begin{tabular}{|c|c|c|}
\hline Group & Dose (mg/kg bw) & Phagocytic index \\
\hline Normal saline & $10 \mathrm{ml} / \mathrm{kg}$ & $2.22 \pm 0.57$ \\
\hline \multirow[t]{2}{*}{ Cyclophosphamide } & $(50 \mathrm{mg} / \mathrm{kg} \mathrm{bw})$ & $02.27 \pm 0.42$ \\
\hline & 50 & $2.84 \pm 0.45^{*}$ \\
\hline \multirow[t]{4}{*}{ RGLE } & 100 & $3.45 \pm 0.32^{* *}$ \\
\hline & 150 & $4.20 \pm 0.39 * *$ \\
\hline & 200 & $5.30 \pm 0.27^{* *}$ \\
\hline & 50 & $3.02 \pm 0.22^{* *}$ \\
\hline \multirow[t]{3}{*}{ RGLM } & 100 & $3.60 \pm 0.45^{* *}$ \\
\hline & 150 & $5.10 \pm 0.31^{* *}$ \\
\hline & 200 & $5.65 \pm 0.16^{* *}$ \\
\hline
\end{tabular}

RGLE: $R$. graveolens leaves ethanol extract, RGLM: $R$. graveolens leaves methanol extract, Values are mean \pm SD, (n=6). One way ANOVA followed by Dunnett's test, ${ }^{*} \mathrm{p}<0.05,{ }^{* *} \mathrm{p}<0.01$, significant when compared with vehicle control group.

Table 4: Effect of ethanolic and methanolic extracts of $R$. graveolens leaves on HA titre and DTH response using SRBCs as an antigen in rats

\begin{tabular}{|c|c|c|c|c|c|c|}
\hline \multirow[t]{2}{*}{ Group } & \multirow{2}{*}{$\begin{array}{l}\text { Dose } \\
\text { (mg/kg bw) }\end{array}$} & \multicolumn{4}{|c|}{ DTH response $(\mathrm{mm}) / \mathrm{h}$} & \multirow[t]{2}{*}{ HA titre } \\
\hline & & 24 & 48 & 72 & 96 & \\
\hline \multirow[t]{2}{*}{ Normal saline } & - & $0.19 \pm 0.05$ & $0.14 \pm 0.04$ & $0.09 \pm 0.02$ & $0.04 \pm 0.01$ & $24.12 \pm 0.22$ \\
\hline & 50 & $0.23 \pm 0.07^{\mathrm{ns}}$ & $0.16 \pm 0.10^{\mathrm{ns}}$ & $0.10 \pm 0.02^{\mathrm{ns}}$ & $0.05 \pm 0.03^{\mathrm{ns}}$ & $27.11 \pm 0.07^{\mathrm{ns}}$ \\
\hline \multirow[t]{4}{*}{ RGLE } & 100 & $0.39 \pm 0.02^{\mathrm{ns}}$ & $0.23 \pm 0.05^{*}$ & $0.13 \pm 0.03^{\mathrm{ns}}$ & $0.07 \pm 0.02^{\mathrm{ns}}$ & $40.56 \pm 3.1^{* *}$ \\
\hline & 150 & $0.6 \pm 0.10^{* *}$ & $0.49 \pm 0.04^{* *}$ & $0.26 \pm 0.04^{* *}$ & $0.13 \pm 0.04^{* *}$ & $52.07 \pm 4.22^{* *}$ \\
\hline & 200 & $0.74 \pm 0.09 * *$ & $0.55 \pm 0.03^{* *}$ & $0.40 \pm 0.03^{* *}$ & $0.25 \pm 0.09 * *$ & $77.13 \pm 4.7^{* *}$ \\
\hline & 50 & $0.24 \pm 0.09^{\mathrm{ns}}$ & $0.18 \pm 0.07^{\mathrm{ns}}$ & $0.11 \pm 0.03^{\mathrm{ns}}$ & $0.07 \pm 0.02^{\mathrm{ns}}$ & $31.02 \pm 0.34^{*}$ \\
\hline \multirow[t]{3}{*}{ RGLM } & 100 & $0.32 \pm 0.11^{\mathrm{ns}}$ & $0.22 \pm 0.05^{\mathrm{ns}}$ & $0.17 \pm 0.04^{*}$ & $0.12 \pm 0.03^{* *}$ & $41.12 \pm 2.55^{* *}$ \\
\hline & 150 & $0.51 \pm 0.07^{\mathrm{ns}}$ & $0.35 \pm 0.04^{* *}$ & $0.20 \pm 0.09 * *$ & $0.14 \pm 0.03^{* *}$ & $62.07 \pm 6.15^{* *}$ \\
\hline & 200 & $0.69 \pm 0.10^{* *}$ & $0.45 \pm 0.05^{* *}$ & $0.32 \pm 0.03^{* *}$ & $0.18 \pm 0.04^{* *}$ & $78.56 \pm 5.43^{* *}$ \\
\hline
\end{tabular}

DTH: Delayed-type hypersensitivity; HA: Hemagglutination antibody titre; RGLE=Ruta graveolens leaves ethanol extract. RGLM= R. graveolens leaves methanol extract; Values are mean $\pm \mathrm{SD},(\mathrm{n}=6)$; One-way ANOVA followed by Dunnett's test, ${ }^{*} p<0.05,{ }^{* *} p<0.01$, significant when compared with control group. 


\section{Haemagglutination antibody titre}

Oral administration of alcoholic extracts of $R$ graveolens leaves produced dose-related significant increase in humoral antibody titer as compared to control group $\left({ }^{*} \mathrm{p}<0.05 ;{ }^{* *} \mathrm{p}<0.01\right)$. Ethanolic extract with different doses 50, 150, 150 and $200 \mathrm{mg} / \mathrm{kg}$ bw significantly elevated haemagglutination antibody titer $27.11 \pm 0.07 \mathrm{~ns}, \quad 40.56 \pm 3.1^{* *}$, $52.07 \pm 4.22^{* *}$ and $77.13 \pm 4.7^{* *}$ while methanolic extract showed $31.02 \pm 0.34^{*}, 41.12 \pm 2.55^{* *}, 62.07 \pm 6.15^{* *}$ and $78.56 \pm 5.43^{* *}$ respectively (table 4). The ethanolic extract at the concentration $200 \mathrm{mg} / \mathrm{kg} \mathrm{bw}$ showed more value of antibody titer as compared to methanolic extract.

\section{Delayed-type hypersensitivity reaction}

Delayed type of hypersensitivity response to SRBC was calculated as a measure of paw oedema thickness (mm) for 50, 100, 150 and 200 $\mathrm{mg} / \mathrm{kg}$ bw of each animal after the treatment with ethanolic and methanolic extracts and compared with control. An increased in paw oedema thickness was calculated after $+24,+48,+72$ and $+96 \mathrm{~h}$. The results showed that methanolic extract showed more value of delayed type hypersensitivity response as compared to ethanolic extract (table 4). In our study, foot volume was enhanced after Ruta graveolens treatment of both the extract suggested cell-mediated immune enhancement by SRBC.

\section{DISCUSSION}

Neutrophil adherence was analyzed by the initial measurement of total leukocyte (TLC) and differential leukocyte count (DLC) from the blood samples. Results indicated that TLC and \% of neutrophil count in fiber treated blood samples were lower than untreated blood samples. Circulation of immune cells is essential for maintaining an effective immune defense network. The TLC was found to be increased in the extracts immunonized group, which may be due to the fall in the corticosterone levels and increased glucocorticoids levels that affect the circulation pattern of immune cells $[15,16]$. This might be due to the upregulation of the $\beta 2$ integrins, present on the surface of the neutrophils through which they adhere firmly to the nylon fibres [17]. Ethanolic and methanolic extracts of $R$ graveolens leaves when administered orally, significantly increased adhesion of neutrophils to nylon fibers which interrelate to the process of margination of cells in blood vessels. This might be due to the up-regulation of the $\beta 2$ integrins, present on the surface of the neutrophil through which they adhere firmly to the nylon fibers [17]. Hence, it was concluded that $R$. graveolens extracts caused stimulation of neutrophil towards the site of inflammation.

Rate of carbon clearance is the measured of competency of the reticuloendothelial system and its granulopoetic activity [18]. The faster removal of carbon particles has been correlated with the enhanced phagocytic activity. An increased in the phagocytic index in terms of carbon particles from the blood is suggestive for activation of WBC. Phagocytosis by macrophages is important against the smaller parasites and its effectiveness is markedly enhanced by opsonization of the parasite with antibodies and complement $\mathrm{C} 3 \mathrm{~b}$ leading to more rapid clearance of parasite from blood [19]. The phyto-constituents of the plant may be responsible for incite complementary receptors (CR1, CR2, CR3, CR3b and CR3bi) of rats, which in turn eliminate carbon particles (the antigen) by phagocytosis. It is supposed that many of the receptors become active due to the exposure of the extract.

The humoral immunity involves the interaction of B cell with antigens and subsequently proliferating and differentiating into antibody producing cells. Antibody functions as the effectors of the humoral response by binding with antigens and neutralizing it or facilitating its elimination by cross-linking to form latex that is more readily ingested by phagocytic cells [20]. The results showed that alcoholic extracts of Ruta graveolens leaves may be enhanced the level of IgM, IgG, and are capable of influencing Bcells, which in turn synthesize or secrete antibodies to increase the antibody molecules linked with SRBC, which leads to subsequent agglutination.

The DTH response directly correlated with T-lymphocytes especially T-DTH-lymphocytes, therefore; increased the effect on cell-mediated immunity. T-lymphocytes get sensitized when they are challenged by any antigen and converted into lymphoblasts and secrets lymphokines, and attract the scavenger cells to the site of reaction. The increased response indicates that leaves extracts has a stimulating effect on B-lymphocytes and macrophages killing activity through NO release by stimulating $\mathrm{T}$ cell for the hypersensitivity reaction.

\section{CONCLUSION}

In the present investigations; phytochemical screening of ethanolic extract of Ruta graveolens leaves revealed the presence of alkaloids, steroids, phenolics, tannins, flavonoids while methanolic extract revealed the presence of alkaloids, flavonoids, steroids and glycosides as essential phytoconstituents and responsible for stimulating both cellular as well as humoral immune responses. The extracts not only potentiate nonspecific immune response but also effectively improve humoral and cell-mediated immunity. Thus, from the results obtained, it can be concluded that Ruta graveolens has therapeutic potential and could be served as an effective immunomodulatory candidate.

\section{ACKNOWLEDGEMENT}

Authors are grateful to Head Department of Botany and Pharmaceutical Sciences, Dr. H. S. Gour Central University, Sagar, M. P., India, for providing laboratory facilities and University Grant Commission (UGC), New Delhi, India, for providing financial assistance.

\section{CONFLICTS OF INTERESTS}

\section{Declared none}

\section{REFERENCES}

1. Shivaprasad HN, Kharya MD, Rana AC, Mohan S. Preliminary immunomodulatory activities of aqueous extract of Terminalia chebula. Pharm Biol 2006;44:32-4.

2. Fenichet RL, Chirigos MA. Immune modulation agents and their mechanism. New York: Dekker; 1984. p. 704.

3. Kuttan G. Immunomodulatory effect of some is naturally occuring sulphur containing compounds. J Ethnopharmacol 2000;72:93-9.

4. Ratheesh M, Helen A. Anti-inflammatory activity of Ruta graveolens linn on carrageenan-induced paw edema in wistar male rats. Afr J Biotechnol 2007;6:1209-11.

5. Oliva A, Kumudini MM, Wedge DE, Harries D, Hale AL, Aliotta G, et al. Natural fungicides from Ruta graveolens L. leaves including a new quinolone alkaloid. J Agric Food Chem 2003;51:890-6.

6. Pandey P, Mehta A, Hajra S. Evaluation of antimicrobial activity of Ruta graveolens stem extracts by disc diffusion method. J Phytol 2011;3:92-5.

7. Pandey P, Mehta Aajra S, John J, Mehta P . Anthelmintic activity of Ruta graveolens L. leaves extract. Int J Phytomed Related Indus 2010;2:240-3.

8. Pandey P, Mehta A, Hajra S, John J, Mehta P. Antioxidant property, total phenolic content and inhibition of the $\alpha$-amylase activity of Ruta graveolens L. leaves extract. J Pharm Res 2011;4:1735-7.

9. Preethi KC, Kuttan G, Kuttan R. Anti-tumour activity of Ruta graveolens extract. Asian Pacific J Cancer Prevention 2006;7:439-43.

10. Trease GE, Evans MC. Textbook of pharmacognosy. 12th ed. Balliere, Tindall, London; 1983. p. 343-83.

11. Ghosh MN Fundamentals of Experimental Pharmacology. Scientific Book Agencies, Calcutta, India; 1971. p. 84-8.

12. Wilkonson PC. Neutrophil adhesion test, a handbook of experimental pharmacology. 1st Ed. Springer-Verlag, Berlin 1978;1:109-10.

13. Cheng W, Li J, You T, Hu C. Antiinflammatory and Immunomodulatory activities of the extracts from the inflorescence of Chrysanthemum indicum Linn. J Ethnopharmacol 2005;101:334-7.

14. Puri A, Saxena R, Saxena RP, Saxena KC. Immunomodulant agents from Andrographis paniculata. J Nat Prod 1993;56:995-9.

15. Kumar SVS, Mishra SH. Hepatoprotective activity of extracts from Pergularia daemia Forsk against carbon tetrachlorideinduced toxicity in rats. Pharmacogn Mag 2007;3:187-91. 
16. Sprent J, Tough DF. Lymphocyte lifespan and memory. Science 1994;265:1395-400.

17. Kumar SR, Narayanaperumal JP, Rathisamy SD. Immunomodulatory activity of Triphala over neutrophil functions. Biol Pharm Bull 2005;28:1398-403.

18. Mishra SN, Ratnavali B. $1^{\text {st }}$ edition. Varanasi: Chaukambha Surbharti Prakashan; 2005. p. 1008-133.

19. Roitt I, Brostoff J, Male D. In: Immunology. 3rd Edition, MosbyYear Book Ltd., London; 1993. p. 7.
20. Gokhale AB, Damre AS, Saraf MN. Investigations into the immunomodulatory activity of Argyreia speciosa. J Ethnopharmacol 2003;84:109-14.

\section{How to cite this article}

- $\quad$ Pinkee Pandey, Archana Mehta, Subhadip Hajra. Evaluation of the immunomodulatory activity of the alcoholic extracts of ruta Graveolens leaves. Int J Pharm Pharm Sci 2016; 8(11):332-336. 